\title{
PERENCANAAN JARINGAN BACKBONE METRO ETHERNET KOTA SEMARANG TAHUN 2028 MENGGUNAKAN ALGORITMA DYSART DAN GEORGANAS SERTA METODE HUNGARIAN DAN FORECASTING KRUITHOF'S DOUBLE FACTOR
}

\author{
Sekar Nirmakumala*), Sukiswo dan Ajub Ajulian Zahra \\ Departemen Teknik Elektro, Universitas Diponegoro \\ Jl. Prof. Sudharto, SH, Kampus UNDIP Tembalang, Semarang 50275, Indonesia \\ ${ }^{*}$ E-mail: sekar_nirma@yahoo.com
}

\begin{abstract}
Abstrak
Teknologi Metro Ethernet merupakan perkembangan dari teknologi ethernet berbasis IP yang dapat diimplementasikan dalam area jaringan metropolitan Kota Semarang. Sifat masyarakat yang konsumtif akan kebutuhan telekomunikasi menyebabkan meningkatnya jumlah trafik dari tahun ke tahun. Hal ini mendorong penyedia layanan telekomunikasi untuk melakukan perencanaan infrastruktur jaringan dengan kualitas yang baik. Penelitian ini berfokus pada perencanaan jaringan backbone Metro Ethernet di Kota Semarang untuk kebutuhan bandwidth 10 tahun mendatang. Perencanaan dilakukan berdasarkan node existing di Kota Semarang dan rute yang optimal diperoleh dengan metode Hungarian untuk membentuk topologi ring. Forecasting trafik dilakukan dengan metode Kruithof's double factor untuk memperoleh prediksi trafik point-to-point sebagai dasar dimensioning jaringan terhadap parameter utilisasi link berdasarkan standar QoS PT. Telkom Area Network Semarang untuk menentukan kapasitas link. Jaringan backbone Metro Ethernet di Kota Semarang pada tahun 2028 mendatang terdapat 11 node yang membentuk topologi multi-ring. Hasil forecasting menunjukkan beban trafik total pada tahun 2028 mencapai 2.300,371 Gbps. Hasil perencanaan jaringan menunjukkan bahwa kebutuhan kapasitas link terbesar pada tahun 2028 mencapai 6 x $100 \mathrm{~Gb}$ pada dua link SPL <->JHR dan CDI<$>$ BMK dan kapasitas link terkecil adalah 2 x $10 \mathrm{~Gb}$ pada link GNK<->MPH dan MKG<->TUG.
\end{abstract}

Kata Kunci: Metro Ethernet, Forecasting trafik, Dimensioning jaringan, Utilisasi link, Travelling Salesman Problem.

\begin{abstract}
Metro Ethernet technology is a development of IP-based Ethernet technology that can be implemented in the metropolitan area network of Semarang City. The nature of the society that is consumptive of telecommunication needs causes an increase in the amount of traffic from year to year. This encourages telecommunications service providers to plan network infrastructure with good quality. This research focuses on planning the Metro Ethernet backbone network in the city of Semarang for bandwidth requirements in the next 10 years. Planning is based on existing nodes in Semarang City and the optimal route is obtained by Hungarian method to form the ring topology. Traffic forecasting is done by the Kruithof's double factor method to obtain point-to-point traffic predictions as the basis for network dimensioning of link utilization parameters based on PT. Telkom Area Network Semarang QoS standards to determine link capacity. Metro Ethernet backbone network in Semarang City in the next 2028 there are 11 nodes that form a multi-ring topology. The forecasting results show that the total traffic load in 2028 reached 2,300.37 Gbps. Network planning results show that the largest link capacity requirement in 2028 reaches $6 \times 100 \mathrm{~Gb}$ on SPL<->JHR and CDI<->BMK links and the smallest link capacity is $2 \times 10 \mathrm{~Gb}$ on the GNK<->MPH and MKG<->TUG links.
\end{abstract}

Keywords: Metro Ethernet, Traffic forecasting, Network dimensioning, Link utilization, Travelling Salesman Problem.

\section{Pendahuluan}

Teknologi telekomunikasi masa kini telah berkembang dengan pesat dan menjadi kebutuhan primer untuk gaya hidup masyarakat di kota Semarang. Terlebih lagi didukung oleh sifat masyarakat yang konsumtif yang menyebabkan bertambahnya beban trafik telekomunikasi dari tahun ke tahun. Hal ini mendorong para penyedia layanan telekomunikasi untuk menyediakan infrastruktur jaringan yang mampu melayani pelanggan dengan kualitas yang baik dengan kapasitas perangkat yang memadai.

Teknologi Metro Ethernet merupakan salah satu perkembangan dari teknologi ethernet yang dapat menempuh jarak berskala perkotaan yang dilengkapi berbagai fitur seperti pada jaringan ethernet secara umum. 
Teknologi Metro Ethernet dapat dijadikan suatu solusi dalam area jaringan metropolitan Kota Semarang dan menawarkan biaya pembuatan serta pemeliharaan yang relatif murah. Pembangunan infrastruktur jaringan Metro Ethernet yang dapat melayani pelanggan dengan kualitas pelayanan yang baik, diperlukan perencanaan yang baik pula agar nilai investasi yang ditanamkan optimal.

Penelitian ini berfokus pada perancangan topologi jaringan backbone Metro Ethernet di Kota Semarang untuk kebutuhan 10 tahun mendatang berdasarkan hasil forecasting trafik dan dimensioning jaringan. Perancangan topologi jaringan dilakukan berdasarkan pada sentral/node topologi existing milik salah satu penyedia layanan telekomunikasi di Kota Semarang. Rute yang optimal untuk mendukung faktor ekonomis pada link jaringan diselesaikan dengan Travelling Salesman Problem dengan metode Hungarian berdasarkan pertimbangan jarak antar sentral [1-3]. Forecasting trafik dilakukan dengan metode Kruithof's double factor berdasarkan laju pertumbuhan trafik per tahun untuk mengetahui ramalan beban trafik point-to-point pada tahun yang akan datang [4-6]. Hasil forecasting trafik digunakan sebagai dasar dimensioning jaringan untuk menentukan kapasitas link yang dibutuhkan meggunakan parameter utilisasi link berdasarkan standarisasi Quality of Service yang berlaku pada PT. Telkom Indonesia Area Network Semarang untuk menghasilkan perencanaan jaringan yang optimal.

\section{Metode}

Perencanaan jaringan Metro Ethernet di Kota Semarang dilakukan berdasarkan diagram alir pada Gambar 1 yang ditampilkan dalam bentuk tahapan-tahapan sistematis.

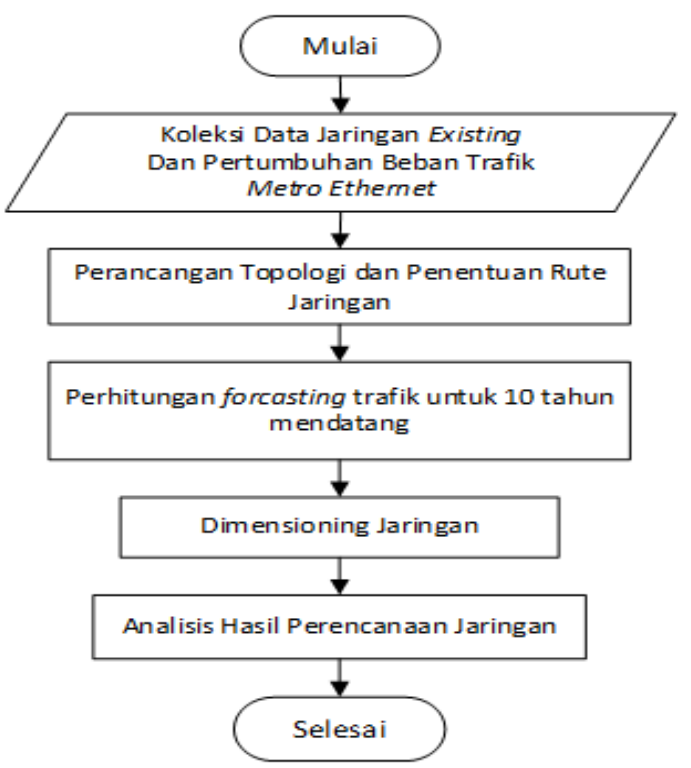

Gambar 1. Metode perencanaan jaringan Metro Ethernet.

\subsection{Perancangan Topologi Jaringan}

Pada penelitian ini terdapat 11 node yang akan dirancang sebagai topologi baru untuk melayani kebutuhan pelanggan Metro Ethernet pada tahun mendatang. 10 node merupakan node existing pada wilayah Kota Semarang yang koordinatnya sesuai dengan jaringan saat ini, kemudian salah satunya merupakan node daerah Kabupaten Semarang yang dipilih yaitu node Ungaran (UNR) dengan pertimbangan beban trafik yang menuju daerah tersebut cukup besar. Kemudian ditambah dengan 1 node Mijen (MJN) yang merupakan pengalihan dari node awal yaitu node Boja (BJA). Pengalihan disesuaikan dengan peta struktur ruang wilayah Kota Semarang. Gambar 3 menunjukkan lokasi node Metro Ethernet yang akan dirancang di Kota Semarang dengan koordinat peletakkan node dapat dilihat pada Tabel 1.

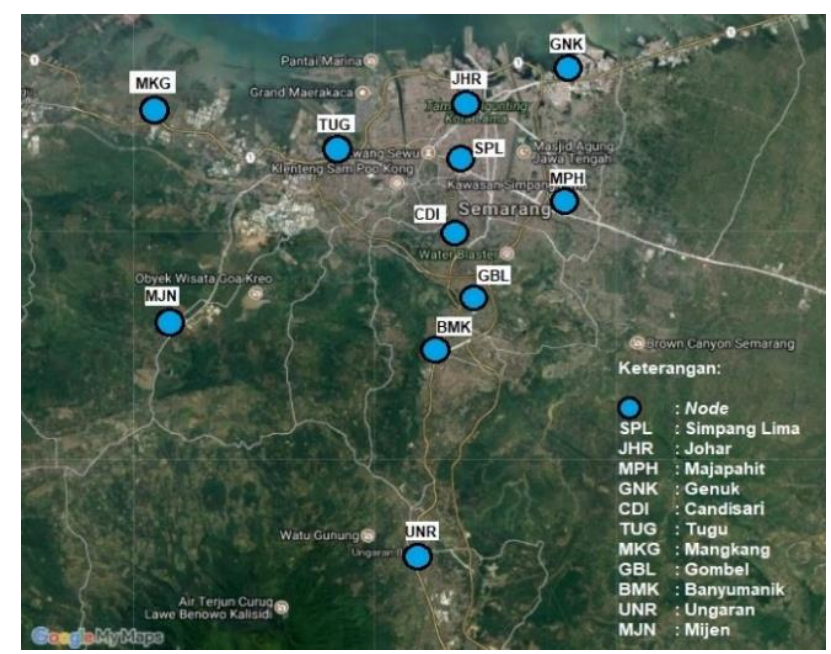

Gambar 2. Perencanaan lokasi node Metro Ethernet Kota Semarang.

Tabel 1. Koordinat lokasi node.

\begin{tabular}{llll}
\hline No & Nama Node & $\mathbf{X}$ (Longitude) & Y (Latitude) \\
\hline $\mathbf{1}$ & CDI & 110.4194 & -7.0195 \\
$\mathbf{2}$ & JHR & 110.424830 & -6.970389 \\
$\mathbf{3}$ & SPL & 110.422126 & -6.991442 \\
$\mathbf{4}$ & MJN & 110.315782 & -7.054561 \\
$\mathbf{5}$ & MKG & 110.310282 & -6.972696 \\
$\mathbf{6}$ & TUG & 110.376654 & -6.987408 \\
$\mathbf{7}$ & GBL & 110.426718 & -7.045152 \\
$\mathbf{8}$ & UNR & 110.408861 & -7.149660 \\
$\mathbf{9}$ & BMK & 110.412369 & -7.063919 \\
$\mathbf{1 0}$ & MPH & 110.460029 & -7.007903 \\
$\mathbf{1 1}$ & GNK & 110.461154 & -6.956602 \\
\hline
\end{tabular}

Rute yang dipilih untuk jalur link merupakan jalan raya arteri primer dan arteri sekunder yang menghubungkan antar node untuk memudahkan pemasangan kabel transmisi dan pemeliharaan agar dapat berjalan secara efektif dan efisien. Perhitungan matriks jarak minimum antar node dari hasil pengamatan google map dapat dilihat pada Gambar 3 dengan satuan jarak dalam kilometer. 


\begin{tabular}{l|rrrrrrrrrrr} 
& GBL & JHR & GNK & MPH & CDI & SPL & TUG & MKG & BMK & UNR & MJN \\
\hline GBL & 0 & 10,7 & 16,1 & 9,6 & 4 & 7,6 & 13 & 21,6 & 3,5 & 13 & 26,5 \\
JHR & 10,7 & 0 & 4,8 & 7 & 6,8 & 2,9 & 6,4 & 14,4 & 12,2 & 22,4 & 18,1 \\
GNK & 16,1 & 4,8 & 0 & 10 & 11 & 8,9 & 11 & 26,9 & 18 & 27,4 & 22,5 \\
MPH & 9,6 & 7 & 10 & 0 & 6,9 & 5 & 10,8 & 18,5 & 14,1 & 21,6 & 22,2 \\
CDI & 4 & 6,8 & 11 & 6,9 & 0 & 3,9 & 8,1 & 17,4 & 5,5 & 15 & 21 \\
SPL & 7,6 & 2,9 & 8,9 & 5 & 3,9 & 0 & 5,7 & 13,8 & 9,3 & 18,8 & 17,2 \\
TUG & 13 & 6,4 & 11 & 10,8 & 8,1 & 5,7 & 0 & 8,3 & 15 & 25,3 & 11,7 \\
MKG & 21,6 & 14,4 & 26,9 & 18,5 & 17,4 & 13,8 & 8,3 & 0 & 28,3 & 37,7 & 11,5 \\
BMK & 3,5 & 12,2 & 18 & 14,1 & 5,5 & 9,3 & 15 & 28,3 & 0 & 10,3 & 23,2 \\
UNR & 13 & 22,4 & 27,4 & 21,6 & 15 & 18,8 & 25,3 & 37,7 & 10,3 & 0 & 21,8 \\
MJN & 26,5 & 18,1 & 22,5 & 22,2 & 21 & 17,2 & 11,7 & 11,5 & 23,2 & 21,8 & 0
\end{tabular}

Gambar 3. Matriks jarak antar node Metro Ethernet.

\subsubsection{Penentuan Node Konsentrator}

Salah satu diantara 11 node yang sudah ditentukan akan berperan sebagai node konsentrator yang akan menghubungkan semua node menuju jaringan WAN. Penentuan lokasi konsentrator pada perencanaan ini menggunakan algoritma Dysart dan Georganas berdasarkan matriks jarak antar node pada Gambar 4. Contoh penentuan letak konsentrator dengan langkahlangkah sebagai berikut:

1. Membuat daftar $11(\mathrm{~N})$ node pada topologi baru.

2. Memilih sejumlah node tetangga $\mathrm{k}=2$ yang mempunyai jarak paling dekat dari setiap node.

3. Menghitung jumlah frekuensi pemunculan (p) dari node ke-1 sampai ke-11, di mana $(p)=1,2, \ldots ., 6$, dengan nilai frekuensi pemunculan maksimum $\mathrm{F}=6$.

Tabel 2. Penentuan lokasi konsentrator dengan $k=2$.

\begin{tabular}{llc}
\hline Node & $\begin{array}{c}\text { Daftar Node dan sejumlah 2 } \\
\text { node tetangga terdekat }\end{array}$ & $\begin{array}{c}\text { Frekuensi } \\
\text { Pemunculan }\end{array}$ \\
\hline GBL & GBL, BMK, CDI & 4 \\
JHR & JHR, SPL, GNK & 4 \\
GNK & GNK, JHR, SPL & 2 \\
MPH & MPH, SPL, CDI & 1 \\
CDI & CDI, SPL, GBL & 5 \\
SPL & SPL, JHR, CDI & 6 \\
TUG & TUG, SPL, JHR & 3 \\
MKG & MKG, TUG, MJN & 2 \\
BMK & BMK, GBL, CDI & 3 \\
UNR & UNR, BMK, GBL & 1 \\
MJN & MJN, MKG, TUG & 2 \\
\hline
\end{tabular}

4. Semua node dikelompokkan sesuai dengan frekuensi pemunculan (p) masing-masing kedalam daftar $S(p)$. yaitu sebagai berikut:
$\mathrm{S}(1)=\mathrm{MPH}, \mathrm{UNR}$
$\mathrm{S}(2)=\mathrm{GNK}, \mathrm{MKG}, \mathrm{MJN}$
$\mathrm{S}(3)=\mathrm{TUG}, \mathrm{BMK}$
$\mathrm{S}(4)=\mathrm{GBL}, \mathrm{JHR}$
$\mathrm{S}(5)=\mathrm{CDI}$
$\mathrm{S}(6)=\mathrm{SPL}$

5. Lokasi konsentrator yang dipilih pertama kali yaitu node yang memiliki frekuensi pemunculan maksimum $\mathrm{F}=6$ pada daftar $\mathrm{S}(6)$ yaitu node $\mathrm{SPL}$.

6. Kemudian pilihan selanjutnya ditentukan melalui ratarata frekuensi pemunculan ditambah 1 dengan perhitungan KM menggunakan persamaan (2.1), yaitu:

$$
\begin{aligned}
& K M=\left(\frac{(1 \times 2)+(2 \times 3)+(3 \times 2)+(4 \times 2)+(5 \times 1)+(6 \times 1)}{11}\right)+1 \\
& K M=4
\end{aligned}
$$

Node yang ditambahkan sebagai pilihan yaitu node yang mempunyai frekuensi pemunculan (p) di mana $\mathrm{KM} \leq(\mathrm{p})<(\mathrm{F})$ dalam daftar $\mathrm{S}(\mathrm{p})$ yaitu node $4 \leq(\mathrm{p})<$ 11, maka node yang dipilih adalah node GBL, JHR, dan CDI.

7. Selanjutnya melakukan perbandingan penentuan lokasi konsentrator dengan variasi sejumlah node tetangga $\mathrm{k}$ $=3$, 4, dan 5. Kemudian dipilih node konsentrator yang mempunyai frekuensi pemunculan maksimum diantara keempat variasi.

\subsubsection{Penentuan Rute Jaringan Baru}

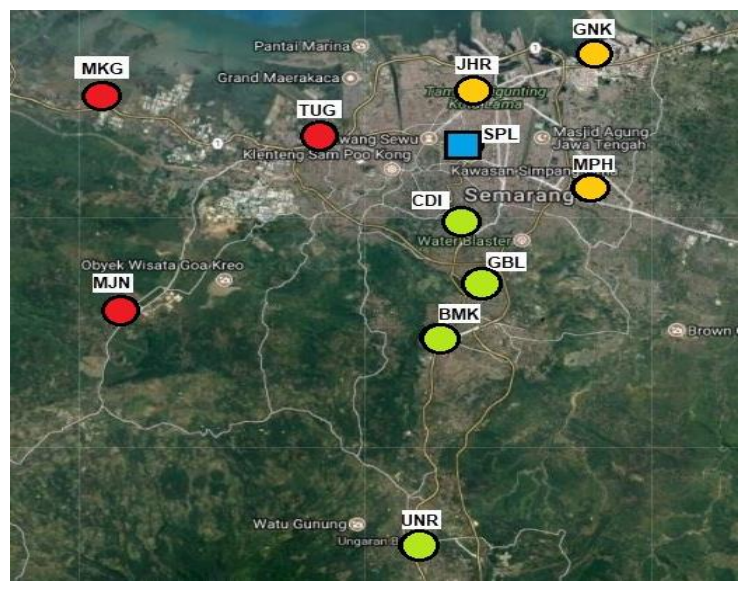

Gambar 4. Pembagian node berdasarkan kelompok ring.

Topologi ring yang diterapkan pada perencanaan ini memiliki jumlah maksimal node yang dihubungkan pada satu ring adalah lima. Gambar 4 menunjukkan pengelompokkan ring dilakukan berdasarkan tiga daerah cakupan di kota Semarang yaitu daerah Semarang Barat sebagai ring 1 disimbolkan dengan node berwarna merah, Semarang Tengah sebagai ring 2 disimbolkan dengan node berwarna kuning, dan Semarang Timur sebagai ring 3 disimbolkan dengan node berwarna hijau.

\subsubsection{Metode Hungarian}

Node-node yang sudah dibagi pada masing-masing daerah ring akan dirutekan berdasarkan Traveling salesman problem dengan metode Hungarian dari data matriks jarak antar node untuk memperoleh cost minimum. Contoh penentuan rute untuk matriks jarak node kelompok ring 1: 


\begin{tabular}{c|cccc|c} 
& SPL & TUG & MKG & MJN & Min. \\
\hline SPL & & 5,7 & 13,8 & 17,2 & 5,7 \\
TUG & 5,7 & & 8,3 & 11,7 & 5,7 \\
MKG & 13,8 & 8,3 & & 11,5 & 8,3 \\
MJN & 17,2 & 11,7 & 11,5 & & 11,5
\end{tabular}

Gambar 5. Matriks jarak node kelompok ring 1 metode Hungarian.

Langkah-1 Kurangkan setiap baris dengan nilai cost terkecil dalam baris yang bersangkutan.

\begin{tabular}{c|cccc} 
& SPL & TUG & MKG & MJN \\
\hline SPL & & 0 & 8,1 & 11,5 \\
TUG & 0 & & 2,6 & 6 \\
MKG & 5,5 & 0 & & 3,2 \\
MJN & 5,7 & 0,2 & 0 & \\
\hline Min. & 0 & 0 & 0 & 3,2
\end{tabular}

Gambar 6. Matriks pengurangan baris metode Hungarian langkah-1.

Langkah-2 Kurangkan setiap kolom dengan nilai cost minimum pada masing-masing kolom yang bersangkutan.

\begin{tabular}{c|cccc} 
& SPL & TUG & MKG & MJN \\
\hline SPL & & 0 & 8,1 & 8,3 \\
TUG & 0 & & 2,6 & 2,8 \\
MKG & 5,5 & 0 & & 0 \\
MJN & 5,7 & 0,2 & 0 &
\end{tabular}

Gambar 7. Matriks pengurangan kolom metode Hungarian langkah-2.

Langkah-3 Menghitung nilai penalti nol pada kolom SPL dengan menjumlah nilai minimum dari deret barisnya dengan nilai minimum pada deret kolomnya

\begin{tabular}{c|cccc} 
& SPL & TUG & MKG & MJN \\
\hline SPL & & $0(8.1)$ & 8,1 & 8,3 \\
TUG & $0(8.1)$ & & 2,6 & 2,8 \\
MKG & 5,5 & $0(0)$ & & $0(2.8)$ \\
MJN & 5,7 & 0,2 & $0(2.8)$ &
\end{tabular}

Gambar 8. Matriks perhitungan nilai penalti dari nol metode Hungarian langkah-3.

Langkah-4 Memilih rute antar node dengan penutupan garis kolom dan baris pada nol yang memiliki nilai penalti tertinggi dan merupakan nilai nol satu-satunya pada baris dan kolom tersebut.

\begin{tabular}{|c|c|c|c|c|}
\hline & SHL & TUG & MKG & MJN \\
\hline SPL & & $0(8 ., 1)$ & 8,1 & $\begin{array}{l}8,3 \\
2 \\
\end{array}$ \\
\hline MKG & 5 & $0(0)$ & & $0(2,8)$ \\
\hline MJN & 5.7 & 0,2 & $0(2,8)$ & \\
\hline
\end{tabular}

Gambar 9. Pemilihan rute metode Hungarian langkah-4.
Matriks akan berkurang menjadi matriks $3 \times 3$ dengan menghilangkan baris TUG dan kolom SPL yang sudah dipilih sebagai rute sebelumnya. Baris SPL dan kolom TUG nilainya dikosongkan karena rute TUG - SPL sudah dipilih.

\begin{tabular}{c|ccc} 
& TUG & MKG & MJN \\
\hline SPL & & 8,1 & 8,3 \\
MKG & 0 & & 0 \\
MJN & 0,2 & 0 &
\end{tabular}

Gambar 10. Pengurangan matriks metode Hungarian langkah-4.

Langkah-5 Memastikan kembali apakah setiap baris dan kolom memiliki nilai nol, jika belum maka perlu dilakukan kembali langkah-1 dan langkah-2 untuk langkah selanjutnya. Pengoptimalan baris dan kolom serta perhitungan penalti terus dilakukan hingga matriks terus berkurang dan ditemukan hasil akhir penyelesaian masalah pemilihan rute yang membentuk loop untuk topologi ring.

\subsection{Forecasting trafik}

Forecasting trafik dilakukan berdasarkan rata-rata pertumbuhan trafik per tahun menggunakan metode kruithof's double factor. Pertumbuhan trafik per tahun diperoleh dengan melakukan asumsi trafik point-to-point topologi baru berdasarkan topologi existing yang digunakan untuk melakukan estimasi total trafik originating dan terminating di setiap sentral pada tahun mendatang. Estimasi total trafik diramalkan meningkat secara linear hingga 10 tahun mendatang

Tabel 3. Hasil asumsi trafik topologi baru.

\begin{tabular}{|c|c|c|c|c|c|}
\hline \multirow{2}{*}{ No. } & \multirow{2}{*}{ Link } & \multicolumn{4}{|c|}{ Volume Trafik (Gbps) } \\
\hline & & 2015 & 2016 & 2017 & 2018 \\
\hline \multirow[t]{2}{*}{1} & $\mathrm{SPL} \rightarrow \mathrm{MJN}$ & 18,708 & 25,386 & 7,675 & 14,276 \\
\hline & MJN $\rightarrow$ SPL & 5,922 & 9,559 & 5,722 & 7,723 \\
\hline \multirow[t]{2}{*}{2} & MJN $\rightarrow$ MKG & 5,452 & 7,398 & 2,554 & 3,823 \\
\hline & MKG $\rightarrow$ MJN & 0,058 & 0,139 & 1,043 & 2,414 \\
\hline \multirow[t]{2}{*}{3} & MKG $\rightarrow>$ TUG & 0,005 & 0,066 & 0,083 & 0,954 \\
\hline & TUG $\rightarrow$ MKG & 0,239 & 0,324 & 0,672 & 1,809 \\
\hline \multirow[t]{2}{*}{4} & TUG $\rightarrow$ SPL & 0,709 & 2,486 & 3,840 & 5,709 \\
\hline & SPL $\rightarrow$ TUG & 0,266 & 0,361 & 6,715 & 12,815 \\
\hline \multirow[t]{2}{*}{5} & $\mathrm{SPL} \rightarrow \mathrm{JHR}$ & 0,319 & 0,433 & 26,595 & 38,368 \\
\hline & $\mathrm{JHR} \rightarrow \mathrm{SPL}$ & 0,234 & 0,318 & 22,873 & 62,670 \\
\hline \multirow[t]{2}{*}{6} & JHR $\rightarrow$ GNK & 0,201 & 0,273 & 1,570 & 2,412 \\
\hline & GNK $\rightarrow$ JHR & 0,103 & 0,440 & 0,604 & 1,305 \\
\hline \multirow[t]{2}{*}{7} & GNK $\rightarrow$ MPH & 0,496 & 0,674 & 0,076 & 0,763 \\
\hline & $\mathrm{MPH} \rightarrow \mathrm{GNK}$ & 2,552 & 3,462 & 0,312 & 1,400 \\
\hline \multirow[t]{2}{*}{8} & MPH $\rightarrow$ SPL & 3,808 & 5,168 & 21,228 & 59,495 \\
\hline & $\mathrm{SPL} \rightarrow \mathrm{MPH}$ & 7,435 & 10,089 & 25,679 & 35,664 \\
\hline \multirow[t]{2}{*}{9} & $\mathrm{SPL} \rightarrow \mathrm{CDI}$ & 6,894 & 9,355 & 16,507 & 23,427 \\
\hline & $\mathrm{CDI} \rightarrow \mathrm{SPL}$ & 3,430 & 4,955 & 21,991 & 57,941 \\
\hline \multirow[t]{2}{*}{10} & $\mathrm{CDI} \rightarrow \mathrm{BMK}$ & 13,533 & 18,664 & 27,514 & 73,070 \\
\hline & $\mathrm{BMK} \rightarrow \mathrm{CDI}$ & 9,269 & 12,577 & 26,836 & 40,116 \\
\hline \multirow[t]{2}{*}{11} & BMK $\rightarrow$ UNR & 8,007 & 10,865 & 10,128 & 16,688 \\
\hline & UNR $\rightarrow$ BMK & 1,424 & 1,834 & 2,545 & 4,817 \\
\hline \multirow[t]{2}{*}{12} & UNR $\rightarrow$ GBL & 6,169 & 9,894 & 14,469 & 27,323 \\
\hline & GBL $\rightarrow$ UNR & 18,345 & 24,893 & 26,479 & 52,876 \\
\hline \multirow[t]{3}{*}{13} & $\mathrm{GBL} \rightarrow \mathrm{SPL}$ & 24,194 & 34,353 & 10,829 & 21,059 \\
\hline & $\mathrm{SPL} \rightarrow \mathrm{GBL}$ & 4,457 & 5,950 & 1,622 & 5,819 \\
\hline & Total & 142,230 & 199,916 & 286,160 & 574,737 \\
\hline
\end{tabular}




\subsubsection{Metode Kruithof's Double Factor}

Kruithof's double factor adalah salah satu metode forecasting yang digunakan untuk menentukan trafik mendatang dari satu tempat ke tempat yang lain (trafik $A_{i j}$ ) dalam matriks trafik. Tujuan dari metode ini adalah untuk mencari konfigurasi beban trafik terbaik antara 2 node/sentral.

\begin{tabular}{c|cccc|c} 
DARI & & & & \\
\multicolumn{1}{c|}{$\mathbf{K E}$} & $\mathbf{1}$ & $\mathbf{I}$ & $\mathbf{J}$ & $\mathbf{N}$ & $\mathbf{\Sigma} \mathbf{O}$ \\
\hline $\mathbf{1}$ & $A_{(11)}$ & & & $A_{(1 n)}$ & $O_{(1)}$ \\
$\mathbf{I}$ & & $A_{(i i)}$ & $A_{(i j)}$ & & $O_{(i)}$ \\
$\mathbf{J}$ & & $A_{(j i)}$ & $A_{(j j)}$ & & $O_{(j)}$ \\
$\mathbf{N}$ & $A_{(n 1)}$ & & & $A_{(n n)}$ & $O_{(n)}$ \\
\hline $\mathbf{\Sigma T}$ & $T_{(1)}$ & $T_{(i)}$ & $T_{(j)}$ & $T_{(n)}$ & $\mathbf{A}$
\end{tabular}

Gambar 11. Matriks trafik.

Keterangan:

$A_{(i j)}$ adalah trafik dari $i$ ke $j$

$A_{(j i)}$ adalah trafik dari $j$ ke $i$

$A_{(i i)}$ adalah trafik lokal sentral $i$

$O_{(i)}$ adalah jumlah seluruh trafik originating sentral $i$

$T_{(j)}$ adalah seluruh trafik terminating sentral $j$

Trafik point-to-point waktu yang akan datang didapatkan dari penyesuaian terhadap baris dengan persamaan (2) dan melakukan penyesuaian terhadap kolom menggunakan persamaan (3)

$$
\begin{aligned}
& A_{i j}(n)=\frac{A_{i j}(n-1)}{O_{i}(n-1)} \cdot O_{i}(t) \\
& A_{i j}(n)=\frac{A_{i j}(n-1)}{T_{j}(n-1)} \cdot T_{j}(t)
\end{aligned}
$$

Keterangan:

$$
\begin{array}{ll}
n & =\text { iterasi ke } n \\
O_{i}(t) & =\text { trafik originating sentral } i \text { pada tahun ke- } t \\
T_{j}(t) & =\text { trafik terminating sentral } j \text { pada tahun ke- } t
\end{array}
$$

Jika total trafik originating dan terminating pada iterasi ke$n$ telah sesuai dengan estimasi total trafik waktu yang akan datang, maka perhitungan iterasi telah berakhir dan konfigurasi optimum telah didapat.

\subsection{Dimensioning Jaringan}

Parameter QoS yang menjadi tolok ukur untuk melakukan pendimensian jaringan adalah parameter utilisasi link. Nilai utilisasi setiap link dipengaruhi oleh seberapa besar beban trafik telah membebani kapasitas link terkait, maka formula untuk memperoleh hasil perhitungan utilisasi yaitu:

$$
\text { Utilisasi }=\frac{\text { Beban trafik }}{\text { Kapasitas link }} \times 100 \%
$$

Estimasi kapasitas link pada perencanaan topologi baru ini akan disesuaikan dengan utilisasi kondisi normal. Kabel transmisi yang akan di terapkan adalah fiber optik dengan kapasitas $10 \mathrm{~Gb}, 40 \mathrm{~Gb}$, dan $100 \mathrm{~Gb}$ berdasarkan teknologi terbaru yang sudah diterapkan pada topologi existing. Parameter utilisasi berdasarkan standar PT. Telkom Indonesia dapat dilihat pada Gambar 12.

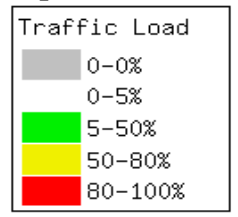

Gambar 12. Standar utilisasi link PT. Telkom Indonesia[9].

Contoh pendimensian pada Tabel 4 untuk link SPL-MJN. Beban trafik diantara kedua arah link tersebut yang paling besar 79,54 Gbps diasumsikan sebagai utilisasi standar

\begin{tabular}{|c|c|c|c|c|}
\hline No & Link & $\begin{array}{c}\text { Trafik } \\
2028 \\
\text { (Gbps) }\end{array}$ & $\begin{array}{c}\text { Trafik } 2028 \times 2 \\
\text { (Gbps) }\end{array}$ & $\begin{array}{c}\text { Kapasitas } \\
\text { Link }\end{array}$ \\
\hline \multirow[t]{2}{*}{1} & SPL $\rightarrow$ MJN & 79,54 & 159,08 & \multirow{2}{*}{$2 \times 100 \mathrm{~Gb}$} \\
\hline & MJN $\rightarrow$ SPL & 28,43 & 56,86 & \\
\hline \multirow[t]{2}{*}{2} & MJN $\rightarrow$ MKG & 15,84 & 31,67 & \multirow{2}{*}{$1 \times 40 \mathrm{~Gb}$} \\
\hline & MKG $\rightarrow$ MJN & 11,02 & 22,04 & \\
\hline \multirow[t]{2}{*}{3} & MKG $\rightarrow$ TUG & 3,38 & 6,75 & \multirow{2}{*}{$2 \times 10 \mathrm{~Gb}$} \\
\hline & TUG $\rightarrow>$ MKG & 7,74 & 15,47 & \\
\hline \multirow[t]{2}{*}{4} & TUG -> SPL & 21,69 & 43,39 & \multirow{2}{*}{$1 \times 100 \mathrm{~Gb}$} \\
\hline & SPL $\rightarrow$ TUG & 55,39 & 110,79 & \\
\hline \multirow[t]{2}{*}{5} & SPL $\rightarrow>$ JHR & 161,99 & 323,97 & \multirow{2}{*}{$6 \times 100 \mathrm{~Gb}$} \\
\hline & JHR -> SPL & 266,54 & 533,08 & \\
\hline \multirow[t]{2}{*}{6} & JHR -> GNK & 14,04 & 28,09 & \multirow{2}{*}{$1 \times 40 \mathrm{~Gb}$} \\
\hline & GNK -> JHR & 8,54 & 17,08 & \\
\hline \multirow[t]{2}{*}{7} & GNK $\rightarrow$ MPH & 4,41 & 8,82 & \multirow{2}{*}{$2 \times 10 \mathrm{~Gb}$} \\
\hline & $\mathrm{MPH} \rightarrow \mathrm{GNK}$ & 8,03 & 16,06 & \\
\hline \multirow[t]{2}{*}{8} & MPH $\rightarrow$ SPL & 249,38 & 498,75 & \multirow{2}{*}{4 x $100 \mathrm{~Gb}$} \\
\hline & $\mathrm{SPL} \rightarrow \mathrm{MPH}$ & 132,99 & 265,98 & \\
\hline \multirow[t]{2}{*}{9} & SPL $\rightarrow$ CDI & 82,13 & 164,27 & \multirow{2}{*}{4 x $100 \mathrm{~Gb}$} \\
\hline & CDI $\rightarrow$ SPL & 236,07 & 472,13 & \\
\hline \multirow[t]{2}{*}{10} & $\mathrm{CDI} \rightarrow \mathrm{BMK}$ & 275,12 & 550,24 & \multirow{2}{*}{$6 \times 100 \mathrm{~Gb}$} \\
\hline & BMK $\rightarrow$ CDI & 139,36 & 278,72 & \\
\hline \multirow[t]{2}{*}{11} & BMK $\rightarrow$ UNR & 49,21 & 98,43 & \multirow{2}{*}{$1 \times 100 \mathrm{~Gb}$} \\
\hline & UNR $\rightarrow$ BMK & 12,55 & 25,10 & \\
\hline \multirow[t]{2}{*}{12} & UNR -> GBL & 101,43 & 202,86 & \multirow{2}{*}{$4 \times 100 \mathrm{~Gb}$} \\
\hline & GBL $\rightarrow$ UNR & 164,40 & 328,80 & \\
\hline \multirow[t]{2}{*}{13} & $\mathrm{GBL} \rightarrow \mathrm{SPL}$ & 126,94 & 253,89 & \multirow{2}{*}{$2 \times 100 \mathrm{~Gb}$} \\
\hline & $\mathrm{SPL} \rightarrow \mathrm{GBL}$ & 44,21 & 88,43 & \\
\hline
\end{tabular}
normal 50\%, maka bandwidth yang dibutuhkan adalah 79,54 Gbps x $2=159,08$ Gbps. Penentuan kapasitas link yang mencukupi adalah $2 \times 100 \mathrm{~Gb}$. Dimensioning seluruh link dapat dilihat pada Tabel 4.

\begin{tabular}{|c|c|c|c|c|c|c|c|c|}
\hline \multirow{2}{*}{ No } & \multicolumn{2}{|c|}{$k=2$} & \multicolumn{2}{|c|}{$k=3$} & \multicolumn{2}{|c|}{$k=4$} & \multicolumn{2}{|c|}{$k=5$} \\
\hline & Node & (p) & Node & (p) & Node & (p) & Node & (p) \\
\hline 1 & SPL & 6 & SPL & 10 & SPL & 11 & SPL & 11 \\
\hline 2 & CDI & 5 & CDI & 7 & CDI & 9 & CDI & 11 \\
\hline 3 & JHR & 4 & JHR & 5 & JHR & 8 & JHR & 10 \\
\hline 4 & GBL & 4 & & & & & MPH & 8 \\
\hline
\end{tabular}

Tabel 4. Dimensioning kapasitas link.

3. Hasil dan Analisa

3.1. Penentuan Lokasi Konsentrator

Tabel 5. Hasil penentuan lokasi node konsentrator. 
Pada Tabel 5 dapat dilihat secara keseluruhan bahwa SPL selalu memiliki frekuensi pemunculan (p) maksimum dan merupakan pilihan pertama sebagai konsentrator. Berdasarkan hasil secara keseluruhan, node SPL merupakan node dengan lokasi strategis untuk dijadikan sebagai node konsentrator.

\subsection{Penentuan Rute Jaringan}

Kelompok ring 1 merupakan kelompok ring bagian Semarang Barat yang memiliki empat anggota node yaitu node SPL, TUG, MKG, dan MJN, dengan node SPL sebagai konsentrator. Pencarian rute untuk kelompok ring 1 dengan metode Hungarian diperoleh rute sebagai berikut: Rute $1=$ TUG - SPL

Rute $2=$ MJN - MKG

Rute $3=$ SPL - MJN

Rute $4=$ MKG - TUG

Cost total yang dilalui sesuai rute SPL-MJN-MKG-TUGSPL adalah 17,2 + 11,5 + 8,3 + 5,7 = 42,7 Km. Rute SPLMJN-MKG-TUG-SPL merupakan satu-satunya rute optimal untuk topologi ring bagian Semarang Barat.

Kelompok ring 2 merupakan kelompok ring bagian Semarang Timur yang memiliki empat anggota node yaitu node SPL, JHR, GNK, dan MPH, dengan node SPL sebagai konsentrator. Pencarian rute untuk kelompok ring 2 didapatkan dua pilihan rute sebagai berikut:
Rute pilihan pertama:
Rute pilihan kedua:
Rute $1=$ JHR - GNK
Rute $1=$ GNK - JHR
Rute $2=$ MPH - SPL
Rute $2=$ SPL - MPH
Rute $3=$ SPL - JHR
Rute 3 = JHR - SPL
Rute $4=$ GNK - MPH
Rute $4=$ MPH - GNK

Rute pilihan pertama yaitu SPL-JHR-GNK-MPH-SPL memiliki cost total $2,9+4,8+10+5=22,7 \mathrm{~km}$. Rute pilihan kedua yaitu SPL-MPH-GNK-JHR-SPL memiliki cost total $5+10+4,8+2,9=22,7 \mathrm{~km}$. Kedua rute pilihan yang dihasilkan adalah sama, namun hanya saja arahnya yang berbeda, maka rute yang optimal yang dipilih untuk ring daerah Semarang Timur adalah rute pilihan pertama yaitu SPL-JHR-GNK-MPH-SPL.

Kelompok ring 3 merupakan kelompok ring bagian Semarang Tengah yang memiliki lima anggota node yaitu node SPL, GBL, BMK, UNR, dan CDI, dengan node SPL sebagai konsentrator. Pencarian rute untuk kelompok ring 3 didapatkan sebagai berikut:

Rute pilihan pertama:

Rute $1=$ SPL - CDI

Rute $2=\mathrm{BMK}-\mathrm{UNR}$

Rute $3=\mathrm{GBL}-\mathrm{SPL}$

Rute $4=$ UNR - GBL

Rute $5=\mathrm{CDI}-\mathrm{BMK}$
Rute pilihan pertama yaitu SPL-CDI-BMK-UNR-GBLSPL memiliki cost total 3,9 + 5,5 + 10,3 + 13 + 7,6 = 40,3 $\mathrm{km}$. Rute pilihan kedua yaitu SPL-GBL-BMK-UNRCDI-SPL dengan cost total 7,6 + 3,5 + 10,3 + 15+3,9= $40,3 \mathrm{~km}$. Jarak antar node pada rute pilihan pertama memiliki nilai maksimum sebesar $13 \mathrm{~km}$, sedangkan pada rute pilihan kedua nilai maksimumnya adalah $15 \mathrm{~km}$, maka rute pilihan pertama merupakan node yang optimal untuk ring pada daerah Semarang Timur yaitu SPL-CDI-BMKUNR-GBL-SPL. Semakin minimum jarak antar node maka akan menghemat pemasangan kabel transmisi antar node.

Hasil penentuan rute link secara keseluruhan untuk topologi ring berdasarkan metode Hungarian dari ketiga daerah kelompok ring yang akan diterapkan pada jaringan Metro Ethernet yang dirancang dapat dilihat pada Gambar 13.

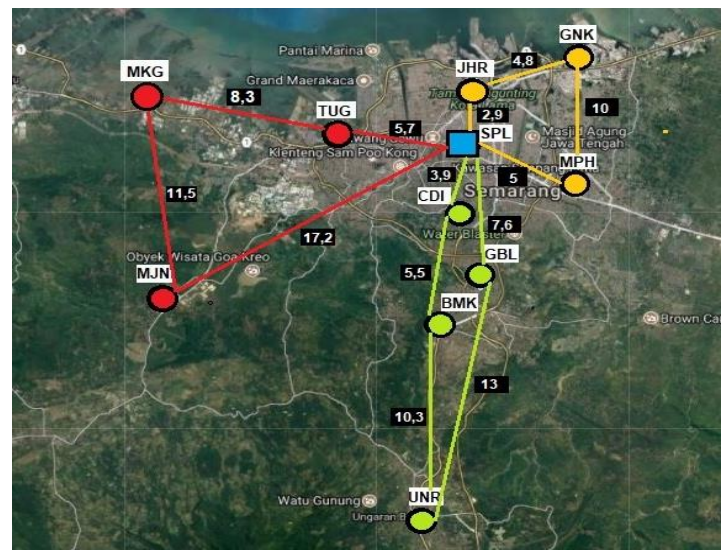

Gambar 13. Hasil perancangan topologi Metro Ethernet kota Semarang.

\subsection{Forecasting trafik}

Hasil forecasting trafik selama 10 tahun mendatang ditunjukkan pertumbuhannya dalam bentuk trafik total di jaringan maupun trafik point-to-point. Tabel 6 merupakan hasil forecasting pada trafik total dalam keseluruhan jaringan dari tahun sekarang, yaitu 2018 hingga tahun 2028.

Tabel 6. Pertumbuhan beban trafik total jaringan.

\begin{tabular}{ccc}
\hline No & Tahun & Beban Trafik (Gbps) \\
\hline 1 & 2018 & 574,751 \\
2 & 2019 & 747,313 \\
3 & 2020 & 919,875 \\
4 & 2021 & $1.092,437$ \\
5 & 2022 & $1.264,999$ \\
6 & 2023 & $1.437,561$ \\
7 & 2024 & $1.610,123$ \\
8 & 2025 & $1.782,685$ \\
9 & 2026 & $1.955,247$ \\
10 & 2027 & $2.127,809$ \\
11 & 2028 & $2.300,371$ \\
\hline
\end{tabular}


Beban trafik total pada tahun 2028 diprediksi memiliki peningkatan yang cukup besar yaitu mencapai 2.300,371 Gbps. Pertumbuhan rata-rata nilai trafik setiap tahunnya adalah konstan yaitu meningkat sebesar 172,562 Gbps sehingga cenderung bersifat linear. Hal ini dikarenakan pertumbuhan trafik internet akan terus meningkat seiring dengan bertambahnya jumlah pelanggan dari tahun ke tahun.

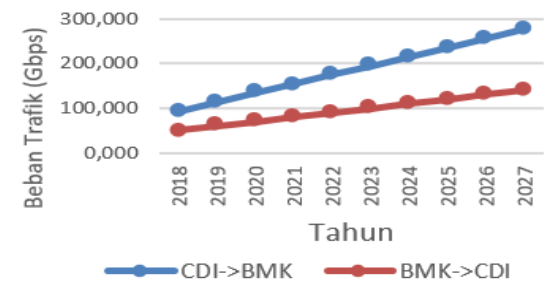

(a)

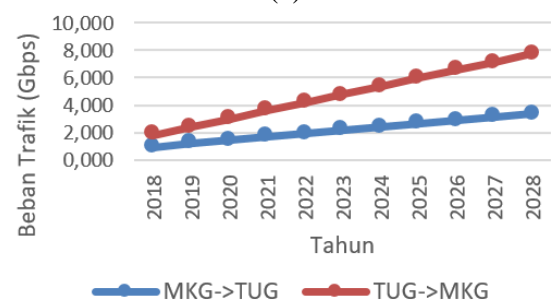

(b)

Gambar 14. Grafik pertumbuhan beban trafik per link selama 10 tahun (a) CDI<->BMK (b) MKG<$>$ TUG

Pertumbuhan trafik point-to-point masing-masing pada link memiliki pertumbuhan yang berbeda-beda, karena konfigurasi beban trafik telah dioptimalkan dengan metode kruithof's double factor untuk disesuaikan dengan estimasi trafik total pada setiap tahun yang diramalkan. Gambar 14 menunjukkan hasil forecasting beban trafik point-to-point secara keseluruhan mengalami peningkatan secara linear sesuai dengan kenaikan estimasi total trafik. CDI->BMK memiliki beban trafik terbesar dari hasil peramalan pada tahun 2028 yaitu sebesar 275,118 Gbps, hal ini disebabkan karena rata-rata beban trafik tahun 2018 pada link tersebut sudah bernilai cukup besar yaitu mencapai 75,070 Gbps dan memiliki pertumbuhan trafik yang besar juga yaitu rata-rata meningkat sebanyak 20,205 Gbps per tahun. Sedangkan trafik MKG->TUG merupakan beban trafik terendah pada tahun 2028 mendatang yaitu 3,377 Gbps, karena mengalami pertumbuhan trafik terkecil yaitu ratarata 0,242 Gbps per tahun dengan beban trafik pada tahun 2018 sebesar 0,954 Gbps.

\subsection{Dimensioning Jaringan}

Hasil dimensioning jaringan ditunjukkan pada Gambar 15 bahwa keseluruhan nilai utilisasi masih berwarna hijau yang artinya link tersebut masih dalam keadaan normal 0$50 \%$, sedangkan terdapat empat link SPL-> TUG, MH$>$ SPL, CDI->SPL, dan GBL->SPL yang sudah berwarna kuning karena melewati rata-rata 5\% hingga $13 \%$ di atas batas normal, di mana nilai tersebut bukan termasuk selisih yang bernilai besar.

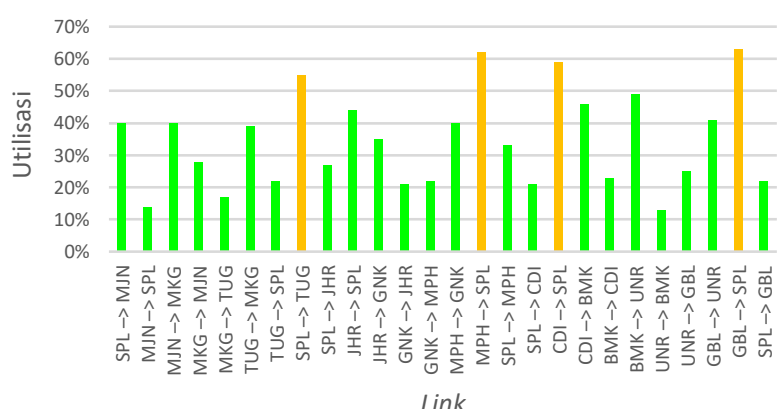

Gambar 15. Grafik nilai utilisasi setiap link dari hasil dimensioning.

Hal ini dikarenakan keempat link tersebut tidak dapat dimaksimalkan lagi saat melakukan dimensioning untuk mendapatkan utilisasi dalam kondisi normal dengan mengingat bahwa aturan penambahan kapasitas link setiap link antar node secara ideal dapat dilakukan sebanyak $2 \mathrm{~N}$. Jika penambahan kapasitas terlalu banyak maka akan terjadi pemborosan dalam pemasangan kabel transmisi. Keempat link tersebut termasuk dalam kondisi peringatan bahwa selama jaringan beroperasi harus selalu dipantau perkembangan utilisasinya seiring bertambahnya beban trafik pada tahun-tahun berikutnya.

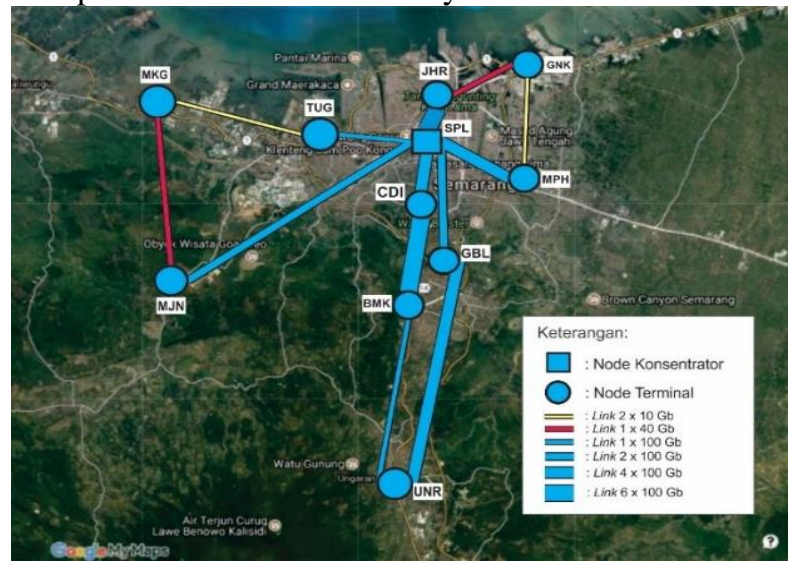

Gambar 16. Hasil perencanaan jaringan Metro Ethernet Kota Semarang tahun 2028.

Gambar 16 menunjukkan bahwa jaringan Metro Ethernet tahun 2028 di Kota Semarang membutuhkan bandwidth dengan kapasitas link terbesar adalah 6 x $100 \mathrm{~Gb}$. Kapasitas link terbesar ini diterapkan pada dua link yaitu SPL <-> JHR dan CDI<->BMK. Sedangkan kapasitas link terkecil yang dibutuhkan adalah $2 \times 10 \mathrm{~Gb}$ yang terdapat pada link GNK<->MPH dan MKG<->TUG. Berdasarkan prediksi kapasitas link yang dibutuhkan, maka modul yang digunakan pada sentral merupakan router switch dengan kapasitas port yang mampu mendukung link dengan kemampuan transmisi 100 Gbps. 
TRANSIENT, VOL. 7, NO. 4, DESEMBER 2018, ISSN: 2302-9927, 956

\section{Kesimpulan}

Berdasarkan hasil perencanaan dan analisis dapat disimpulkan bahwa topologi baru yang optimal untuk jaringan backbone metro ethernet di Kota Semarang membentuk multi-ring dengan node Simpang Lima sebagai konsentrator yang menghubungkan 3 kelompok ring daerah Semarang Barat, Semarang Timur, dan Semarang Tengah dengan minimum cost rute yang diperoleh dengan metode Hungarian. Hasil forecasting trafik total pada tahun 2028 diprediksi memiliki peningkatan mencapai 2.300,371 Gbps dengan pertumbuhan rata-rata trafik setiap tahunnya adalah konstan yaitu meningkat sebesar 172,562 Gbps. Sedangkan hasil forecasting beban trafik point-to-point terbesar terjadi pada link CDI->BMK sebesar 275,118 Gbps dan link MKG-> TUG memiliki beban trafik terendah yaitu 3,377 Gbps. Kebutuhan kapasitas link terbesar pada tahun 2028 mencapai 6 x 100 Gb pada dua link yaitu SPL<$>$ JHR dan CDI<->BMK dan kapasitas link terkecil 2 x 10 Gb pada link GNK<->MPH dan $\mathrm{MKG<->TUG.} \mathrm{Nilai}$ utilisasi link hasil pendimensian jaringan sudah sesuai harapan karena sesuai dengan standar keadaan normal yaitu antara 0-50\%, namun yaitu link SPL-> TUG, MH$>$ SPL, CDI->SPL, dan GBL->SPL melewati batas normal dengan selisih rata-rata 5\% hingga 13\% dari batas normal, di mana nilai tersebut bukan termasuk selisih yang bernilai besar. Keempat link tersebut hanya perlu dipantau kinerjanya selama jaringan beroperasi.

Beberapa saran yang bisa menjadi masukan untuk perencanaan jaringan metro ethernet selanjutnya adalah dapat dilakukan dengan menerapkan teknologi Packet Optical Transport Network (P-OTN) dan dapat juga dikembangkan pada bagian perencanaan jaringan akses Metro Ethernet. Perencanaan jaringan selanjutnya dianjurkan menggunakan software simulasi jaringan untuk mengetahui performasi QoS lainnya dari hasil perencanaan jaringan yang dilakukan.

\section{Referensi}

[1]. G. Petrus B.K dkk, "A New Heuristic Method for Ring Topology Optimization: A Proposal," IEEE. 2017.

[2]. Caturiyati, "Penyelesaian Asymmetric Travelling Salesman Problem dengan Algoritma Hungarian dan Algoritma Cheapest Insertion Heuristic," Staf Pengajar Jurusan Pendidikan Matematika FMIPA UNY, 2008.

[3]. Jadunath Nayak $d k k$, "Hungarian Method to Solve Travelling Salesman Problem with Fuzzy Cost," International Journal of Mathematics Trends and Technology (IJMTT), Vol. 49, No. 5, September 2017.

[4]. Satya Yoga Pratama, "Analisis Performansi Link Pada Jaringan Metro Ethernet Regional Jawa Tengah Menggunakan Simulator Opnet 14.5," Laporan Tugas Akhir, Departemen Teknik Elektro, Universitas Diponegoro, Semarang, 2017.

[5]. The International Telecommunication Union, "Teletraffic Engineering handbook," Geneva, January 2005.

[6]. Kruithof. J, "Telefoonverkehrsrekening”, De Ingenieur, Vol. 52, 1937.

[7]. Dysart, H G and Georganas, "NEWCLUST: An Algorithm for the Topological Design of Two-Level, Multidrop Teleprocessing Networks', IEEE Trans. Commun., Vol. 26, No. 1, January 1978, pp 55-61.

[8]. IEEE Standard for Ethernet, IEEE Std 802.3 ${ }^{\mathrm{TM}}-2012$.

[9]. R. Fauzi, "Pengantar Peramalan Dalam Telekomunikasi," Jurusan Teknik Elektro, Universitas Sumatera Utara digital library, 2004.

[10]. S. N. Hertiana, "Diktat Rekayasa Trafik," Sekolah Tinggi Teknologi Telkom.

[11]. Weathermap Ring $10 G$ Metro Huawei JATENG, PT. Telkom Divisi Regional IV Jawa Tengah.

[12]. Sukiswo, "Konsep Dasar Trafik" Mata Kuliah Rekayasa trafik, Departemen Teknik Elektro, Universitas Diponegoro.

[13]. Metro Ethernet Customer Premise Equipment: Integrated Services Routers, Cisco System.

[14]. Sukiswo, "Teknik Perancangan Jaringan Optik" Mata Kuliah Perencanaan Jaringan, Departemen Teknik Elektro, Universitas Diponegoro. 